\title{
PCR em tempo real para detecção do vírus da doença de Aujeszky
}

[Real time PCR for detection of Aujeszky's disease virus]

\author{
A.A. Fonseca Júnior ${ }^{1}$, A.C. Cotorello ${ }^{1}$, N.L. Dias ${ }^{1}$, R. D'Ambros ${ }^{2}$, R.C. Leite ${ }^{3}$, \\ M.B. Heneimann ${ }^{3}$, J.K.P. Reis ${ }^{3}$ \\ ${ }^{1}$ Laboratório Nacional Agropecuário - Mapa - Pedro Leopoldo, MG \\ ${ }^{2}$ Centro de Diagnóstico em Sanidade Animal - Concórdia, SC \\ ${ }^{3}$ Escola de Veterinária - Universidade Federal de Minas Gerais -Belo Horizonte, MG
}

\begin{abstract}
RESUMO
O objetivo deste trabalho foi desenvolver uma PCR em tempo real (qPCR) para o diagnóstico rápido e sensível da doença de Aujeszky. Os iniciadores amplificaram um fragmento de 123 pares de base do gene codificante da glicoproteína D. A qPCR foi testada em 25 amostras de cérebro de suíno positivas e 85 amostras negativas para DA no isolamento viral e na soroneutralização. A sensibilidade analítica foi calculada com acréscimo de um isolado brasileiro do SuHV-1 titulado em amostras de cérebro de suíno negativas na soroneutralização e na PCR. A técnica apresentou sensibilidade analítica de $10^{-0,5}$ TCID50/50 $\mu \mathrm{L}$. A qPCR foi capaz de distinguir reações inespecíficas devido a dímero de oligonucleotídeos iniciadores ou amplificações, além do alvo designado (evitando, assim, os falsopositivos), e de obter resultados rápidos.
\end{abstract}

Palavras-chave: suínos, qPCR, validação, doença de Aujeszky

\begin{abstract}
The aim of this study was to validate a low-cost real-time PCR for a quick and sensitive diagnosis of the disease. The fluorofore used was a DNA intercalating agent, one of the cheaper detection systems. Primers amplified a 123 base pairs fragment of the gene coding for glycoprotein D. PCR was tested on 25 samples of pig brain positive for $A D$ and 85 samples negative in viral isolation and serum neutralization. The detection limit was calculated on samples of pig brain contaminated with a Brazilian isolate of SuHV-1. The technique had a detection limit of $10^{-0,5}$ TCID50/50 $\mu$ L. PCR was able to distinguish nonspecific reactions due to primer dimers (thus avoiding false positives) and get faster results.
\end{abstract}

Keywords: PCR, Validation, Aujeszky's Disease

\section{INTRODUÇÃO}

A doença de Aujeszky (DA) ou pseudorraiva é uma enfermidade de grande importância na suinocultura (OIE, 2009). O agente etiológico é o herpesvírus suíno tipo 1 (SuHV-1 ou PrV), pertencente à subfamília Alphaherpesvirinae, um grupo de vírus conhecido pela sua rapidez na replicação, efeito citopático e espectro amplo de hospedeiros (Pomeranz et al., 2005). Espécies como cães, gatos e bovinos também são suscetíveis à infecção e apresentam uma encefalite de curso agudo fatal, sendo considerados hospedeiros terminais do vírus, o que diminui sua importância epidemiológica devido à baixa disseminação do vírus por essas espécies animais (Pomeranz et al., 2005).

O primeiro registro da DA no Brasil data de 1908 e, desde então, focos da DA já foram registrados nos estados de Minas Gerais, Rio de Janeiro, São Paulo, Paraná, Santa Catarina e Rio Grande do Sul (Cunha et al., 1998). A enfermidade teve um impacto anual de quase um milhão de reais em Santa Catarina (Zanella, 2001).

Recebido em 3 de junho de 2011

Aceito em 7 de fevereiro de 2013

E-mail: augustofj@yahoo.com.br 
A Instrução Normativa $\mathrm{n}^{\circ} 8$, de 3 de abril de 2007 (Brasil, 2007), prevê a necessidade de cada estado brasileiro criar um plano estadual de combate à DA de acordo com a regulamentação prevista no Plano de Contingência. Prevê-se o diagnóstico por ELISA (triagem ou para gE em caso de vacinação) e teste de neutralização viral. As técnicas de PCR e isolamento viral poderão ser utilizadas como confirmatórias. As atuais metodologias de diagnóstico, como, por exemplo, o isolamento e a neutralização viral, são específicas e muito utilizadas nos laboratórios, mas contam com determinados problemas que podem comprometer a velocidade das análises ou mesmo os resultados. O isolamento e a neutralização viral têm a desvantagem de necessitar de cultivos celulares, o que os torna mais trabalhosos (OIE, 2009). Esses dois métodos ainda necessitam de utilização do próprio vírus, o que pode dificultar seu uso à medida que o programa de erradicação avance e novos níveis de biossegurança sejam indicados para a manipulação do SuHV-1.

Testes baseados na detecção de anticorpos, como ELISA e soroneutralização, dependem da soroconversão do animal. O diagnóstico sorológico realizado durante a fase aguda da doença pode levar a resultados negativos, por serem necessários pelo menos 10 dias, em média, para a detecção dos anticorpos específicos (Jacobs et al., 1996; Kinker et al., 1997). Existe o risco de animais mais jovens morrerem antes da soroconversão, pois são mais suscetíveis aos sinais neurológicos, o que inviabilizaria o diagnóstico sorológico (Kinker et al., 1997). O problema não se resume à fase aguda da infecção, pois animais em estado de latência podem apresentar decaimento do nível de anticorpos, acarretando resultados falsonegativos (McCaw et al., 1997).

A PCR tem grande valia no diagnóstico, inclusive quando se trata de avaliação de animais em inquéritos epidemiológicos (Yoon et al., 2005). De acordo com Bascuñana et al. (1997), no programa de erradicação da DA na Suécia, encontrou-se uma série de animais aparentemente não infectados denominados indivíduos de reação única, que apresentaram resultados positivos para o ELISA para $\mathrm{gB}$ e quase sempre negativos para $\mathrm{gE}$. Por meio da PCR, detectou-se o DNA viral nesses animais. No programa de erradicação dos Estados Unidos, o isolamento viral foi sendo gradualmente substituído pela PCR como método de diagnóstico (USDA, 2008).

A padronização de uma metodologia de diagnóstico baseada em PCR em tempo real (qPCR) implicará benefícios na velocidade e qualidade do diagnóstico da DA. Além das vantagens da PCR convencional, existem outras qualidades inerentes à qPCR. As principais vantagens da qPCR são a rapidez do diagnóstico, a elevada sensibilidade analítica e diagnóstica e o risco mínimo de contaminação por não exigir a manipulação dos amplicons, como nos casos da nested PCR ou semi-nested PCR (Yeh et al., 2009). Outro ponto significativo é a amplificação do DNA do agente e a visualização do resultado sem a necessidade de utilização de eletroforese em gel de agarose como ocorre nas PCRs convencionais. $\mathrm{O}$ objetivo deste trabalho foi padronizar uma PCR em tempo real para diagnóstico da DA.

\section{MATERIAL E MÉTODOS}

O gene codificante para a glicoproteína $\mathrm{D}(\mathrm{gD})$ foi escolhido como alvo para a qPCR por ser altamente conservado no SuHV-1, mas sendo permitido diferenciá-lo de outros herpesvírus, diminuindo, desse modo, a probabilidade de amplificações cruzadas (Pomeranz et al., 2005). Para definição da região de amplificação, fez-se o alinhamento de sequências do gene $\mathrm{D}$ de SuHV-1, herpesvírus bovino 1, herpesvírus bovino 5 , herpesvírus equino 1 , disponíveis no GenBank no programa Bioedit (Hall, 1999). Após verificação das regiões mais conservadas em SuHV-1, o fragmento foi submetido à análise no programa Primer3 para desenho dos iniciadores (Rozen e Skaletsky, 1998). A lista de iniciadores sugeridos pelo programa foi submetida ao programa computacional PrimerBlast (http://www.ncbi.nlm.nih.gov/tools/primerblast/) para análise in silico da especificidade. A qualidade dos iniciadores foi analisada pelo NetPrimer (http://www.premierbiosoft.com/netprimer).

Os oligonucleotídeos iniciadores selecionados foram $\mathrm{gD}-\mathrm{F}$ (GGTCCCCTCGCCCTTCGTC) e $\mathrm{gD}-\mathrm{R}$ (GCCACCGCCTCGTTCAGC) (Integrated DNA Technologies Inc. IDT, Estados Unidos) e produziram um fragmento de 123 pares de base. Os mesmos programas foram utilizados para desenhar e avaliar iniciadores 
para o gene da glyceraldehyde 3-phosphate dehydrogenase (GAPDH) de suíno. Os iniciadores selecionados foram S.scrofa-Green-GAPDH-F (TCCCTGCTTCTACCGCT) e S.scrofa-Green-GAPDHR (ACACGTTGGGGGTGGGGACA) (Integrated DNA Technologies Inc. IDT, Estados Unidos) e produziram um fragmento de 100 pares de base. O objetivo dessa segunda reação foi determinar a presença de inibidores ou falha na extração do DNA em quaisquer amostras de tecido suíno utilizadas no diagnóstico de DA. Qualquer reação negativa para GAPDH invalidaria os resultados para detecção de SuHV-1. Os dois pares de oligonucleotídeos iniciadores foram utilizados em todas as amostras utilizadas.

A amostra-padrão Shope, com título viral de $10^{4,5}$ TCID50/50 $\mu \mathrm{L}$, foi utilizada na padronização da reação. Ainda, foram utilizadas 25 amostras de cérebro de suínos naturalmente infectados pelo SuHV-1, sendo positivos no isolamento e na soroneutralização viral. Essas amostras são provenientes do banco de amostras do laboratório Centro de Diagnóstico de Sanidade Animal (Cedisa) e foram coletadas em focos notificados de DA em Santa Catarina, em 2003. Sessenta amostras de cérebro suíno, 12 de tonsilas, sete de bulbo olfatório e cinco de rim foram coletadas durante o abate de animais provenientes de uma granja sem histórico de DA. Foi realizada uma coleta do sangue dos suínos abatidos. Os animais foram submetidos ao teste de soroneutralização segundo OIE (2009). O DNA de todas as amostras foi extraído a partir de 20-50mg de tecido após descongelamento pelo kit Wizard Genomic DNA Purification (Promega, Estados Unidos), segundo recomendações do fabricante, e armazenado a $20^{\circ} \mathrm{C}$.

Os parâmetros para a padronização utilizados na metodologia a seguir foram realizados conforme o Manual of Diagnostic Tests and Vaccines for Terrestrial Animals 2009 (OIE, 2009) e por Espy et al. (2006).

O termociclador Rotorgene 3000 (Corbett, Austrália) foi utilizado em todos os testes. A reação para detecção do SuHV-1 (qPCR-gD) foi padronizada inicialmente com DNA extraído da amostra Shope, cultivado em células pk15, e a qPCR-GAPDH de tecido de cérebro de suíno.
A determinação da eficiência foi realizada por curva-padrão com amplificação de produtos purificados das PCRs. Os amplicons foram purificados com o kit PCR reaction clean-up (Invitrogen, Estados Unidos), e as concentrações estimadas em espectrofotômetro de luz ultravioleta (Nanovue ${ }^{\circledR}$, GE Healthcare, Estados Unidos). O número de cópias foi estimado de acordo com fórmula definida por Staroscik (2004). Após o cálculo do número de cópias, uma série de curvas-padrão foi feita para determinação da melhor concentração de iniciadores, definindo-se como $\mathrm{R}^{2}$ mínimo 0,99 , eficiência mínima 0,90 e eficiência máxima 1,10 . Todos os resultados foram confirmados pela análise dos picos de dissociação dos amplicons (PD).

A amostra-padrão Shope, cinco amostras do genótipo I e 14 amostras do genótipo II do SuHV-1, isoladas em Minas Gerais, São Paulo, Paraná, Santa Catarina, e Rio Grande do Sul, previamente caracterizadas por Fonseca Jr. et al. (2010a) e Fonseca Jr. et al. (2012), mais as amostras de herpesvírus bovino 1 (BoHV-1, cedido pelo Laboratório de Diagnóstico de Doenças Virais do Lanagro/MG), herpesvírus bovino 5 (BoHV-5, cedido pelo Instituto de Pesquisas Veterinárias Desidério Finamor) e Streptococcus suis (extraído de amostra do Laboratório de Biologia Molecular do Lanagro/MG) foram utilizadas para análise da especificidade analítica.

A sensibilidade analítica da qPCR-gD foi calculada a partir do número de cópias do DNA viral. Após a determinação da melhor concentração dos iniciadores e demais reagentes da reação, os amplicons purificados foram diluídos em série na base 10. A curva-padrão foi feita a partir de triplicatas de cada diluição em três dias consecutivos.

A determinação do limite de detecção (LD) foi realizada a partir de diluição do controle positivo e contaminação de amostras químicas. O DNA foi adicionado em duas concentrações, a $100 \mathrm{ng} / \mu \mathrm{L}$ e entre 300 e $600 \mathrm{ng} / \mu \mathrm{L}$, para se verificar, a partir do limite de detecção, qual a concentração ideal de DNA a ser utilizada nas reações. A amostra- padrão Shope foi diluída em base 10 e utilizada para contaminar amostras de cérebro de suíno negativas para o SuHV-1. As diluições de $-4,-5$ e -6 , equivalentes às 
concentrações $\quad 10^{0,5} \quad$ TCID50/50 $\mu \mathrm{L}, \quad 10^{-0,5}$ TCID50/50 $\mu \mathrm{L}, \quad 10^{-1,5}$ TCID $50 / 50 \mu \mathrm{L}$, foram utilizadas para contaminar sete replicatas biológicas de cada. Cada uma foi extraída independentemente e submetida à qPCR.

O LD foi determinado como a diluição em que todas as amostras fossem positivas. A confirmação foi realizada com contaminação nesse mesmo limite e nova extração independente de sete amostras (sete replicatas biológicas). Estas foram repetidas em três dias diferentes. A análise permite uma falha, garantindo o resultado com $95 \%$ de confiança.

A reprodutibilidade e a robustez foram analisadas de maneira semelhante, sendo aprovadas somente quando todas as amostras testadas apresentassem os resultados esperados. Seis pontos da PCR foram submetidos a análises sucessivas em triplicatas técnicas: três amostras positivas (em diferentes concentrações), uma amostra contaminada no LD, uma amostra negativa com amplificação inespecífica de acordo com testes prévios $(\mathrm{CN})$ e o controle negativo sem molde (NTC, para verificar a formação de dímeros de iniciadores). No teste de reprodutibilidade (RPO), um técnico diferente realizou as análises. No teste de robustez (ROB), as mesmas amostras foram submetidas a duas variações básicas, uma com aumento da inespecificidade da reação, denominado ROB1 $\left(+10 \%\right.$ Taq,$+10 \%$ Primer $,+5 \% \mathrm{MgCl} 2,-1^{\circ} \mathrm{C}$ na temperatura de anelamento) e outra com inibição da reação, denominado ROB2 (-10\% Taq, $-10 \%$ Primer, $-5 \% \mathrm{MgCl} 2,+1^{\circ} \mathrm{C}$ na temperatura de anelamento).

A robustez também foi analisada com três mixes diferentes no equipamento ABI7500 (Applied Biosystems, Estados Unidos), sendo o primeiro desse grupo de reagentes o descrito anteriormente neste trabalho (ROB3) e dois outros adquiridos prontos. Os kits previamente prontos foram Eva Green Master Mix (Biotium, Estados Unidos), denominado ROB4, e Sybr Green Master Mix (Invitrogen, Estados Unidos), denominado ROB5.

A qPCR-gD foi testada nas 85 amostras dos suínos negativos na soroneutralização e em 25 amostras de suínos naturalmente infectados pelo SuHV-1. A principal função desses testes foi detectar possíveis interferentes, reações inespecíficas e sensibilidade em amostras clínicas e em diferentes tecidos. Para essa análise, foi coletado um número de amostras conforme sugerido por Espy et al. (2006).

\section{RESULTADOS}

As melhores concentrações para a qPCR-gD foram definidas como: 7,5 pmoles de cada oligonucleotídeo iniciador (IDT, Estados Unidos), 1,5U GoTaq (Promega, Estados Unidos), $20 \%$ tampão GoTaq incolor 5x, $1,9 \mathrm{mmol} / \mathrm{L} \mathrm{MgCl}_{2}, 1 \mu \mathrm{L}$ de EvaGreen 20x, $8 \%$ DMSO, 200 $\mu \mathrm{mol} / \mathrm{L}$ DNTP, para um volume final de $20 \mu \mathrm{L}$. As melhores condições para a qPCR-GAPDH foram: 5,0pmoles de cada oligonucleotídeo iniciador (IDT, Estados Unidos), 1,5U GoTaq (Promega, Estados Unidos), 20\% tampão GoTaq incolor 5x, $1.9 \mathrm{mmol} / \mathrm{L} \mathrm{MgCl}_{2}, 1 \mu \mathrm{L}$ de EvaGreen 20x, $200 \mu \mathrm{mol} / \mathrm{L}$ DNTP, para um volume de $20 \mu \mathrm{L}$.

As etapas no termociclador para as duas reações foram determinadas como $95^{\circ} \mathrm{C}$ por $5 \mathrm{~min}$ para desnaturação, 40 ciclos a $95^{\circ} \mathrm{C}$ por $25 \mathrm{~s}, 58^{\circ} \mathrm{C}$ por $25 \mathrm{~s}$ e $72^{\circ} \mathrm{C}$ por 20 s com leituras no ciclo de extensão. A curva de desnaturação foi realizada com os seguintes parâmetros: $30 \mathrm{~s}$ a $80^{\circ} \mathrm{C}$ e $3 \mathrm{~s}$ por grau até $99^{\circ} \mathrm{C}$. Os pontos de corte da qPCR$\mathrm{gD}$ foram $0,5 \mathrm{dF} / \mathrm{dT}$ e temperatura de $92,5^{\circ} \mathrm{C}$ e da qPCR-GAPDH foram $0,5 \mathrm{dF} / \mathrm{dT}$ e temperatura de $93,2^{\circ} \mathrm{C}$ (Fig. 1). Houve a formação de pequenos picos em temperatura inferior à temperatura limite no tubo sem DNA molde devido à formação de dímeros de iniciadores. A alteração nas concentrações dos iniciadores não alterou significativamente a formação de dímeros.

Todas as amostras de SuHV-1 foram amplificadas com picos de desnaturação com variação de até $0,5^{\circ} \mathrm{C}$ em relação à amostrapadrão Shope. As amostras de BoHV-1, BoHV-5 e $S$. suis não apresentaram amplificações.

A qPCR foi capaz de detectar até 18,8 cópias/ $\mu \mathrm{L}$, com $\mathrm{R}^{2}$ igual a 0,99 e eficiência de 0,97 . A curva-padrão para qPCR-GAPDH apresentou $\mathrm{R}^{2}$ 0,99 e eficiência 0,99. Quanto mais próximo de 1 o valor de eficiência, melhor a performance da qPCR, o que indica que os produtos gerados praticamente dobram a cada ciclo.

O LD foi confirmado com $10^{-0,5} \mathrm{TCID}_{50} / 50 \mu \mathrm{L}$ na concentração de DNA entre 300 e $600 \mathrm{ng} / \mu \mathrm{L}$, 
com todos os resultados positivos na diluição -5 . Todas as repetições nesse limite foram positivas nas sete amostras testadas nos três dias diferentes (Tab. 1). O teste com amostras acrescidas com o vírus titulado demonstrou que a matriz (tecido animal) pode influenciar na eficiência da reação, como pode ser notado pelos valores de desviopadrão encontrados. $\mathrm{Na}$ análise da curva de desnaturação, picos com temperatura similar ao do controle positivo, mas com $\mathrm{dF} / \mathrm{dT}$ inferior a 0,5, foram desconsiderados. Amostras com $\mathrm{Ct}$ entre 36 e 38 foram consideradas suspeitas, e seu resultado foi confirmado pela curva de desnaturação e por nested PCR realizada conforme Fonseca Jr. et al. (2010b) (Tab. 2). O desvio-padrão $(\sigma)$ dos picos de desnaturação inclui as amostras utilizadas como controle positivo (Tab. 3).

Tabela 1. Desvio-padrão dos Cts e picos de desnaturação na confirmação do LD

\begin{tabular}{|c|c|c|c|c|}
\hline \multirow{2}{*}{ Dia } & \multicolumn{2}{|c|}{$\mathrm{Ct}^{*}$} & \multicolumn{2}{|c|}{ Pico de desnaturação } \\
\hline & $\sigma$ & Média & Média & $\sigma$ \\
\hline 1 & 1,46 & 37,83 & 92,6 & 0,45 \\
\hline 2 & 1,85 & 37,43 & 92,7 & 0,60 \\
\hline 3 & 0,85 & 36,28 & 92,93 & 0,23 \\
\hline
\end{tabular}

*Cycle treshold.

Tabela 2. Valores de $\mathrm{Ct}$ para as amostras clínicas positivas

\begin{tabular}{cc}
\hline Intervalo de $\mathrm{Ct}^{*}$ & Número de amostras \\
\hline 14,4 a 16,13 & 4 \\
18,33 a 19,89 & 6 \\
20,53 a 22,87 & 8 \\
23,85 a 26,96 & 3 \\
29,15 a 29,97 & 2 \\
33,31 & 1 \\
36,41 & 1 \\
\hline
\end{tabular}

*Cycle treshold.

Tabela 3. Desvio-padrão dos Cts e picos de desnaturação na confirmação do LD

\begin{tabular}{ccccc}
\hline Dia & \multicolumn{2}{c}{$\mathrm{Ct}^{*}$} & \multicolumn{2}{c}{ Pico de desnaturação } \\
\cline { 2 - 5 } & $\sigma$ & Média & 92,6 & $\sigma$ \\
\hline 1 & 1,46 & 37,83 & 92,7 & 0,45 \\
2 & 1,85 & 37,43 & 92,93 & 0,60 \\
3 & 0,85 & 36,28 & 0,23 \\
\hline
\end{tabular}

*Cycle treshold.

Os desvios para os Cts foram altos, indicando que o limite de quantificação seria maior, no entanto, como a técnica é puramente qualitativa, os resultados são demonstrados aqui apenas para a análise das variações a que a PCR se sujeita quando há pequenas concentrações de DNA viral em relação ao DNA da matriz.

Os testes de RPO foram realizados por um segundo técnico com as mesmas amostras de tecido suíno, apresentando os resultados esperados. Todas as amostras testadas para a análise da robustez do método obtiveram os resultados esperados. ROB1 resultou em Cts menores devido à maior concentração de reagentes e à diminuição da temperatura de anelamento. ROB2 aumentou os Cts das amostras. Em nenhum dos casos, os resultados geraram problemas na interpretação dos resultados nos picos de desnaturação. Houve amplificação nas repetições das amostras $\mathrm{CN}$ provavelmente devido à formação de dímeros de iniciadores, como se pode notar pela presença de Cts elevados, no entanto esses resultados não ocorreram em conjunto com picos de desnaturação específicos devido ao fato de o início da curva de desnaturação ocorrer em temperatura de $80^{\circ} \mathrm{C}$ (Tab. 4).

Tabela 4. Desvio-padrão dos Cts e picos de desnaturação em RPO e ROB 


\begin{tabular}{|c|c|c|c|c|c|c|}
\hline & \multicolumn{2}{|c|}{ RPO } & \multicolumn{2}{|c|}{ ROB1 } & \multicolumn{2}{|c|}{ ROB2 } \\
\hline Amostra & \multicolumn{2}{|c|}{$\mathrm{Ct}^{*}$} & \multicolumn{2}{|c|}{$\mathrm{Ct}$} & \multicolumn{2}{|c|}{$\mathrm{Ct}$} \\
\hline & Média & $\sigma$ & Média & $\sigma$ & Média & $\sigma$ \\
\hline 3293 & 17,10 & 0,19 & 16,46 & 0,21 & 17,69 & 0,78 \\
\hline 14 & 27,53 & 0,34 & 26,75 & 0,35 & 27,81 & 0,30 \\
\hline 23 & 25,15 & 0,09 & 24,90 & 0,32 & 25,49 & 0,15 \\
\hline $\mathrm{LD}^{*}$ & 35,20 & 1,63 & 39,20 & 0,48 & 38,89 & 0,46 \\
\hline $\mathrm{CN}^{*}$ & 32,31 & 0,35 & 31,97 & 0,07 & 36,82 & 0,51 \\
\hline NTC* & - & - & - & - & - & - \\
\hline PD* & 92,44 & 0,44 & 92,56 & 0,31 & 92,56 & 0,36 \\
\hline
\end{tabular}

*Ct, cycle treshold; $\mathrm{LD}$, limite de detecção; $\mathrm{CN}$, controle negativo (não apresentou picos de desnaturação); NTC, no template control; PD, pico de desnaturação.

Os resultados de ROB3, ROB4 e ROB5 (Tab. 5) demonstraram que a utilização dos mesmos reagentes em um sistema de detecção diferente pode alterar o LD da metodologia. O primeiro fator notado foi a grande diferença entre os PDs esperados. Os maiores ocorreram no equipamento Rotorgene 3000, enquanto cada mix apresentou um PD médio diferente (Tab. 3).

Tabela 5. Desvio-padrão dos Cts e PD nos testes de REP, RPO, ROB

\begin{tabular}{ccccccc}
\hline \multirow{2}{*}{ Amostra } & \multicolumn{2}{c}{ ROB1 } & \multicolumn{2}{c}{ ROB2 } & \multicolumn{2}{c}{ ROB3 } \\
\cline { 2 - 7 } & $\dot{X}$ & $\sigma$ & $\dot{X}$ & $\sigma$ & $\dot{X}$ & $\sigma$ \\
\hline 1 & 25,64 & 0,20 & 20,58 & 0,33 & 19,16 & 0,58 \\
2 & 24,15 & 0,46 & 19,79 & 0,34 & 17,92 & 0,53 \\
3 & 27,65 & 0,47 & 21,50 & 0,45 & 20,71 & 0,62 \\
4 & 23,04 & 0,96 & 18,48 & 0,46 & 16,67 & 0,54 \\
5 & - & - & 33,89 & 0,32 & 33,39 & 0,56 \\
6 & - & - & 35,67 & 0,99 & 34,16 & 0,94 \\
\hline 7 & 21,12 & 0,09 & 17,59 & 1,19 & 15,50 & 0,51 \\
\hline PD & 89,6 & 0,0 & 88,54 & 0,25 & 86,61 & 0,15 \\
\hline
\end{tabular}

O limiar ou ponto de corte foi calculado automaticamente pelo ABI7500, variando discretamente entre os dias de análise. Todas as amostras amplificaram em triplicata em todas as repetições, com exceção daquelas no LD. Neste último caso, o menor número de repetições positivas foi em ROB3, com uma replicata positiva por amostra. Os PDs não foram detectados nessas ocasiões, fator primordial para considerar a reação positiva.

As 25 amostras clínicas positivas testadas obtiveram picos semelhantes à amostra-padrão Shope utilizada como controle positivo. As 85 amostras clínicas de suínos negativos foram negativas também na qPCR. Seis amostras negativas apresentaram picos na curva de desnaturação com $\mathrm{dF} / \mathrm{dT}$ superior a 0,5 , porém com temperaturas menores que a temperatura de corte. Essas amostras foram consideradas negativas. A temperatura de desnaturação média das amplificações específicas foi de $93,66^{\circ} \mathrm{C}$ (desvio-padrão de 0,345 , variância de 0,119 ). Os
Cts encontrados foram diferentes para cada amostra, variando entre 14 e 36 .

\section{DISCUSSÃO}

A OIE dispõe de diversas metodologias de PCR para várias enfermidades de importância veterinária. $\mathrm{O}$ uso da biologia molecular no diagnóstico de doenças provocadas por vírus animais tem uma grande gama de variação nos tipos de reações, de PCRs convencionais a multiplex e tempo real tanto para detecção de agentes patogênicos como para genotipagem (OIE, 2009). A metodologia desenvolvida neste trabalho permitiu uma identificação mais rápida e sensível do SuHV-1, sendo a primeira descrita na literatura consultada com todos os procedimentos de validação necessários. Outros trabalhos para detecção molecular descrevem PCRs para diagnóstico sem mencionarem testes de limite de detecção, repetitividade, reprodutibiliade ou robustez.

A qPCR está sendo cada vez mais utilizada na detecção de agentes infecciosos como vírus e 
bactérias (Ratcliff et al., 2007). Os métodos com agentes intercalantes têm a vantagem de terem um custo mais acessível (Yeh et al., 2009).

Os resultados encontrados neste trabalho permitiram identificar uma técnica confiável no diagnóstico molecular da DA. A qPCR-GAPDH amplificou para todas as amostras testadas, demonstrando-se útil como controle da amostra de DNA. Outra vantagem marcante é a velocidade da reação, pois os resultados não precisam ser fracionados e visualizados em gel de agarose. Devido ao fato de a qPCR utilizar amplicons menores, os ciclos são mais curtos, obtendo-se resultados mais rápidos, em menos de uma hora e meia.

A qPCR-gD foi menos sensível do que a nested PCR descrita por Fonseca Jr. et al. (2010), no entanto ainda apresenta vantagens tanto por ser menos trabalhosa no tempo de execução quanto por diminuir a possibilidade de contaminação (situação bastante preocupante nas nested PCRs). Ambas as metodologias detectaram todas as amostras clínicas testadas, e as amostras com alto $\mathrm{Ct}$, consideradas suspeitas, foram confirmadas pela nested PCR. Esses dois fatores indicam que as técnicas podem ser usadas em conjunto.

Um dos principais problemas encontrados na qPCR com agentes intercalantes é a fluorescência gerada por dímeros de iniciadores (Ponchel et al., 2003). Essa ocorrência é difícil de ser inibida mesmo com a utilização de enzimas do tipo hotstart (Peters et al., 2004). Os dímeros de iniciadores apresentaram $\mathrm{Ct}$ sempre maior do que 35 e valores menores do que $90^{\circ} \mathrm{C}$ na curva de desnaturação. Esses resultados os tornam facilmente distinguíveis de reações positivas para SuHV-1 que tenderam a apresentar Cts menores do que 35 e temperatura de desnaturação maior do que $93^{\circ} \mathrm{C}$.

A qPCR foi testada em diferentes tecidos de suínos. Apenas seis das 110 amostras clínicas testadas apresentaram amplificações inespecíficas, sem, no entanto, apresentarem picos de desnaturação que prejudicassem a interpretação final dos resultados. As reações de qPCR com agentes intercalantes do DNA podem gerar curvas de amplificação devido a dímeros de iniciadores ou interferentes na amostra, o que torna imprescindível a utilização de curvas de desnaturação para interpretação correta dos resultados (Bustin e Nolan, 2004). Todas as amostras de cérebro positivas para o isolamento viral amplificaram na qPCR. Outros trabalhos indicam o gânglio trigêmeo e o bulbo olfatório como matriz para detecção do DNA de SuHV-1 (Bascuñana et al., 1997), porém essas amostras são de coleta mais difícil devido ao tamanho e à localização no encéfalo. Os resultados indicam que cortes do encéfalo de suínos podem ser utilizados eficientemente para detecção do SuHV-1.

As variações na detecção da fluorescência e da temperatura de desnaturação detectadas em algumas amostras e repetições podem estar relacionadas tanto com variações intrínsecas da reação quanto com a quantidade de DNA, pequenas variações iônicas e outros interferentes relacionados com fatores do instrumento.

\section{CONCLUSÕES}

O presente trabalho descreveu uma qPCR para diagnóstico de DA com diversas vantagens sobre métodos clássicos, como, por exemplo, menor tempo de execução, diminuição dos riscos de contaminação das amostras com amplicons e a não utilização de reagentes cancerígenos, como brometo de etídeo, para observação dos resultados.

\section{AGRADECIMENTOS}

Este projeto teve financiamento do INCTPecuária, CNPq, Fapemig e Lanagro/MG Ministério da Agricultura, Pecuária e Abastecimento.

\section{REFERÊNCIAS}

BASCUÑANA， C.R.; BJÖRNEROT, L.; BALLAGI-PORDANY, A. et al. Detection of pseudorabies virus genomic sequences in apparently uninfected "single reactor" pigs. Vet. Mic., v.55, p.37-47, 1997.

BRASIL. Instrução Normativa 8 de três de abril de 2007. Aprova as Normas para o Controle e a Erradicação da Doença de Aujeszky (DA) em suídeos domésticos, a serem observadas em todo o território nacional. Diário Oficial da União. Seção 1, Página 1, 10/04/2007.

BUSTIN, S.A.; NOLAN, T. Pitfalls of Quantitative Real-Time Reverse-Transcription 
Polymerase Chain Reaction. J. Biomol. Tech., v.15, p.155-166, 2004.

CUNHA, E.M.S.; PEIXOTO, Z.M.P.; KOTAIT I. et al. Efficacy of an inactivated Aujeszky's disease virus vaccine: experimental infection of pigs. Br. J. Vet. Res. Anim. Sci., v.35, p. 00-00, 1998.

ESPY, M.J.; UHL, J.R.; SLOAN, L.M., et al. Real-Time PCR in clinical microbiology: applications for routine laboratory testing. Clin. Microbiol. Rev., v.19, p.165-256, 2006.

FONSECA Jr., A.A.; CAMARGOS, M.F.; OLIVEIRA, A.M. et al. Molecular epidemiology of Brazilian pseudorabies viral isolates. Vet. Microbiol., v.141, p.238-245, 2010a.

FONSECA Jr., A.A.; CAMARGOS, M.F.; D’AMBROS, R.M. et al. Diagnóstico e genotipagem do vírus da pseudoraiva por nestedPCR e análise de restrição enzimática. Cienc. Rural, v.40, p.921-927, 2010b.

FONSECA Jr., A.A.; CARMAGOS, M.F.; SALES, M.L. et al. Pseudorabies virus can be classified into five genotypes using partial sequences of ul44. Braz. J. Mic., v.43, p.10021008, 2012.

HALL, T.A. BioEdit: a user-friendly biological sequence alignment editor and analysis program for Windows 95/98/NT. Nucleic Acids Symposium, v.41, p.95-98, 1999.

JACOBS, L.; KIMMAN T.G.; BIANCHI A. et al. Lack of serum antibodies against glycoprotein $\mathrm{E}$ in pseudorabies virus-immune pigs infected with wild-type virus. Am. J. Vet. Res., v.57, p.1525-1528, 1996.

KINKER, D.R.; SWENSON, S.L.; WU, L.L.; ZIMMERMAN, J.J. Evaluation of serological testsfor the detection of pseudorabies $\mathrm{gE}$ antibodies during early infection. Vet. Microbiol., v. 55, n. 1-4, p.99-106, 1997.

McCAW, M.B.; OSORIO, F.A.; WHEELER, J., et al. Effect of maternally acquired Aujeszky's disease (pseudorabies) virusspecific antibody in pigs on establishment of latency and seroconversion to differential glycoproteins after low dose challenge. Vet. Microbiol., v.55, p.91-98, 1997.
PETERS, I.R.; HELPS, C.R.; HALL, E.J. Realtime RT-PCR: considerations for efficient and sensitive assay design. J. Immunol. Methods. v.286, p.203-17, 2004.

POMERANZ, L.E.; REYNOLDS, A.E.; HENGARTNER, C.J. et al. Molecular biology of pseudorabies virus: impact on neurovirology and veterinary medicine. Microbiol. Biol. Rev., v.69, p.462-500, 2005.

PONCHEL, F.; TOOMES, C.; BRANSFIELD, K. et al. Real-time PCR based on SYBR-Green I fluorescence: an alternative to the TaqMan assay for a relative quantification of gene rearrangements, gene amplifications and micro gene deletions. BMC Biotechnology, v.3, p.18, 2003.

RATCLIFF, R.M.; CHANG, G.; KOK, T. et al.. Molecular diagnosis of medical viruses. Cur. Issues Mol. Biol., v.9, p.87-102, 2007.

ROZEN, S.; SKALETSKY, H.J. Primer3. Code available at http://www-genome.wi.mit.edu/ genome_software/other/primer3.html. 1998.

STAROSCIK, A. Calculator for determining the number of copies of a template. Disponível em: http://www.uri.edu/research/gsc/resources/cndna. html. 2004. Acessado em: 20 abril 2009.

OIE (Organização Mundial de Saúde Animal). Manual of Diagnostic Tests and vaccines

for Terrestrial Animals 2009.

YOON, H.A.; EO, S.K.; ALEYAS, A.G. et al. Molecular survey of latent pseudorabies virus infection in nervous tissues of slaughtered pigs by nested and real-time PCR. J. Microbiol., v.43, p.430-436, 2005.

USDA, United States Department of Agriculture, 2008. Pseudorabies (Aujeszky's Disease) and Its Eradication: a review of U.S. experience.

YEH, H.Y.; YATES, M.V.; CHEN, W. et al. Real-time molecular methods to detect infectious viruses. Semin. Cell Dev. Biol., v.20, p.49-54, 2009.

ZANELLA, J.R.C.; MORÉS, N. Estimativa de impacto econômico anual da doença de Aujeszky para a suinocultura do estado de Santa Catarina. Embrapa Suínos e Aves. Comunicado Técnico, 294, 2001. 